\title{
Reinstating the Sense of Partnership in Perioperative Patient's Care. Our Opinion on the Value of Education in Anesthesiology for Surgical Residents
}

\author{
Mikhail Chernov*, Angela Vick, Sujatha Ramachandran, Galina Leyvi and Ellise Delphin \\ Department of Anesthesiology, Montefiore Medical Center, USA
}

Submission: February 14, 2019; Published: February 19, 2019

*Corresponding author: Mikhail Chernov, Montefiore Medical Center, Weiler Hospital1825 Eastchester Avenue Bronx, New York 10461, USA

\begin{abstract}
Background: Patient care outcome in critical situations depends greatly on the quality of communication between providers. Improving communication minimizes the time necessary for an appropriate response - the primary goal for real and simulated clinical experience. However, no simulation can address or create a pathway to each and every real-life scenario. This deficiency can be diminished through non-simulation based Cross-Departmental Training (CDT) - a process designed to help surgical residents acquire basic theoretical knowledge and practical skills used by their anesthesia colleagues.

Methods: 15 PGY 1 residents participated in a month-long course offered by the department of anesthesiology. The curriculum combined didactic material, covering most of the anesthesia-related topics along with its daily practical implementation. A pre-test was provided to participants prior to the course and a post-test was given at the end of training. Residents completed $360^{\circ}$ post-evaluations for the course.

Results: Analysis of the Pre - and Post-tests revealed improved understanding of anesthetic consideration including the preoperative evaluation, monitoring, perioperative pharmacology and physiology. Improvement in anesthesia-related practical skills was appreciated by rotators, anesthesia residents acting as preceptors and attending anesthesiologists. However, the most significant improvements where seen in the participants 'understanding of the anesthesiologist's role in the overall perioperative process, the importance of interdisciplinary communication and their own value as members of the operating room team.
\end{abstract}

Conclusion: Non-simulation based interdisciplinary training for surgical residents at the initial stages of training is a valuable educational tool helping members of the team to effectively cross specialty- related barriers in critical situations.

Keywords: Cross-specialty education; Team building; Training support; Patients care team

\section{Introduction}

Traditionally the operating room (OR) has been viewed as a highly hierarchical system where physician-surgeons were playing a leading role [1]. However, in recent years the OR has undergone tremendous evolution. High complexity of cases, production pressure, time constrains, and associated stress makes an individual leadership concept virtually unsustainable. A solo mentality of individual physicians leads to failures in communication and directly correlates with increased surgical errors [2]. As a result, team-building exercises in the operating room have become a very popular concept. The main goal of every existing team-building exercise in medicine is to improve communication between providers and to create functional protocols designed to minimize the response time and improve clinical outcome in relatively common critical situations [3]. However, despite being a useful educational tool, simulation exercises cannot address every existing unexpected clinical scenario and make clinicians to feel comfortable to cross specialtyrelated barriers during perioperative emergencies. This, at least partially, may be attributed to

a) communication challenges related to each individual specialty, including anesthesiology.

b) undefined sense of shared responsibility over patient's care, and

c) lack of clear leadership model.

The solution to this problem has to be created and addressed at the earliest stages of professional training. Unfortunately, none of the existing educational curriculums in surgery or anesthesiology address these issues. In contrary, contemporary educational approach to surgical training still creates a sense of superiority and unarguable leadership over other members of the 
OR team [4]. Non-simulation based cross-departmental training is designed specifically to eliminate this confusion. This course equally benefits members of both Departments - surgery and anesthesiology by restoring a sense of partnership in patients' care, providing an educational opportunity for surgical residents and a teaching (mentoring) experience for anesthesia residents involved in the process.

\section{Materials and Methods}

The course was based on the assumption that:

a) By creating a greater understanding of the anesthetic perspective on perioperative patient risk factors, surgical staff may participate more fully in adequate preoperative evaluation and optimization of the surgical patient which should reduce the number of case cancellations and delays resulting in better OR efficiency.

b) Improved relationships between the anesthesiology and surgical staff will facilitate interpersonal communication and professional interaction through a structured educational mentorship program in which surgical residents acquire general and surgical subspecialty-related anesthesia knowledge through both didactic and practice-based learning opportunities while gaining an appreciation for the role of teamwork within a perioperative care system with the ultimate goal of enhancing patient care, safety, and satisfaction.

c) Knowledgeable surgical resident colleagues will be capable and willing to assist anesthesiology staff members during intraoperative crises and near-misses.

15 PGY 1 residents from the Departments of Orthopedics and General surgery participated in a month-long course. Prior to the course all residents were provided with Pretest. The Pretest consists of 42 questions designed to assess participants knowledge on specific topics or OR-related activities:

a) Pre-operative clinical assessment, monitoring, basics of pharmacology and physiology of anesthetics

b) Communication, teamwork and leadership in the operating room

c) Team behavior in unexpected critical situations.

During the entire course PGY 1 residents were fully functional and involved in the same activities as CA1 residents. The course curriculum was tailored for maximal engagement of participants through daily lectures, OR activities and end-of- the day debriefings provided by the senior anesthesia staff. To enhance the educational potential of the course and build up a sense of partnership, CA 3 residents were involved as preceptors. To finalize the activity, all participants were encouraged to complete a Posttest, a $360^{\circ}$ evaluation of the entire course and curriculum. Anesthesia preceptors were evaluating participants progress as well.

\section{Results}

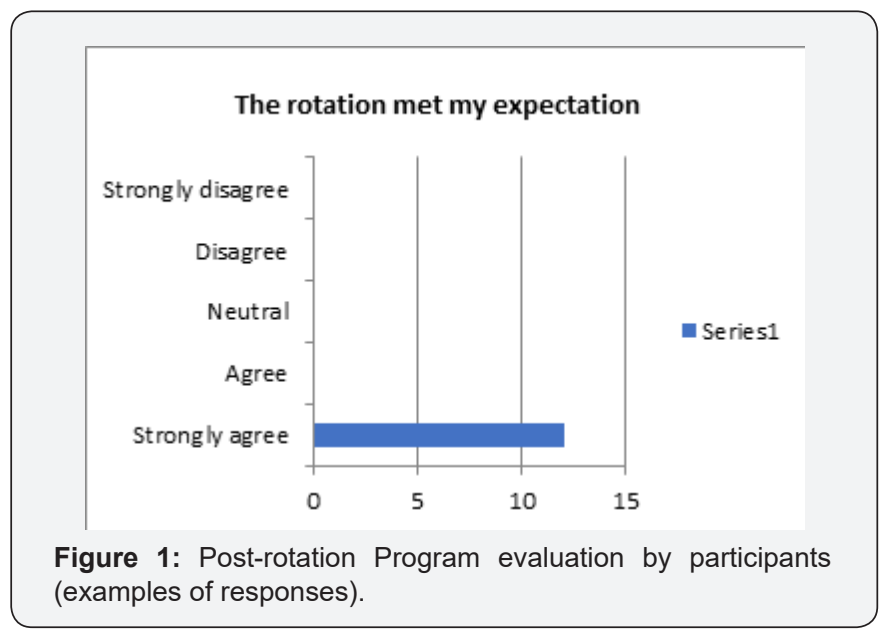

The small number of participants does not allow statistical analysis of some aspects of the program. However, the common impression of the importance of the program in general (Figure 1) and the following elements of it, in particular, were expressed by overwhelming majority of participants:

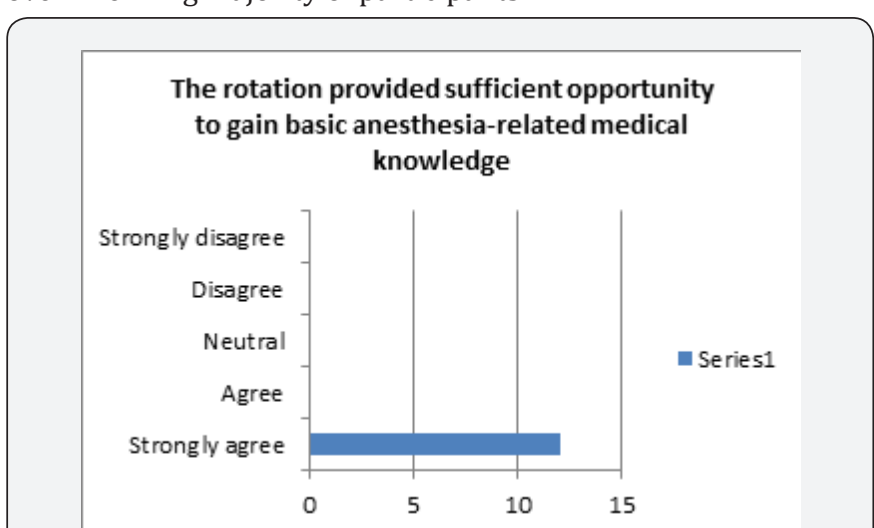

Figure 2: Post-rotation Program evaluation by participants (examples of responses).

a. Rotation provided an opportunity to gain or improve anesthesia-related medical knowledge (Figure 2).

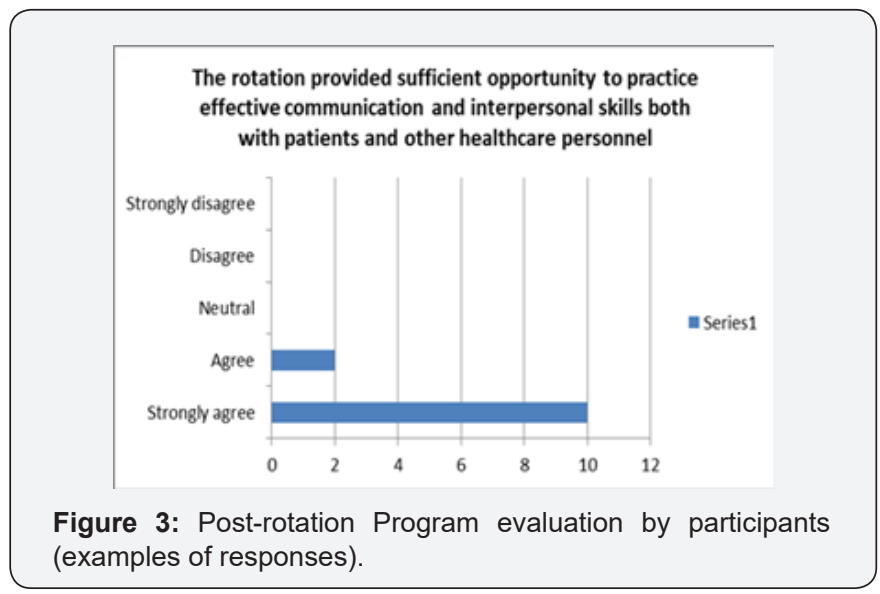

b. Rotation improved interpersonal communication with the anesthesia staff and other members of the team (Figure 3). 
c. Rotation helped to better define the role of surgical trainees as a valuable member of the perioperative team, their ability to utilize an existing resource and more effectively help anesthesia providers in critical situations (Figure $4 \& 5$ ).

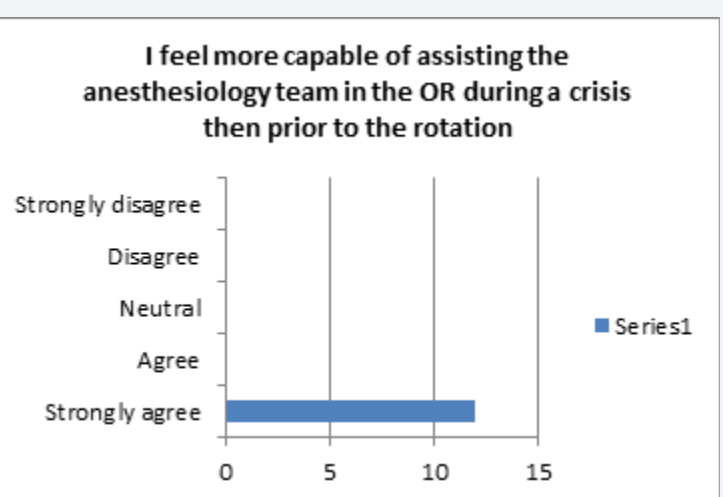

Figure 4: Post-rotation Program evaluation by participants (examples of responses).

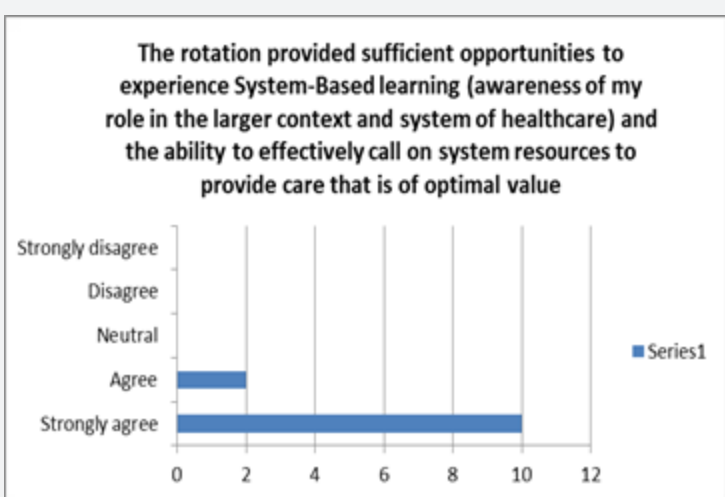

Figure 5: Post-rotation Program evaluation by participants (examples of responses). d. Rotation provided an opportunity to better understand perioperative process and improve necessary practical skills, including line placement and airway management (Figure 6).

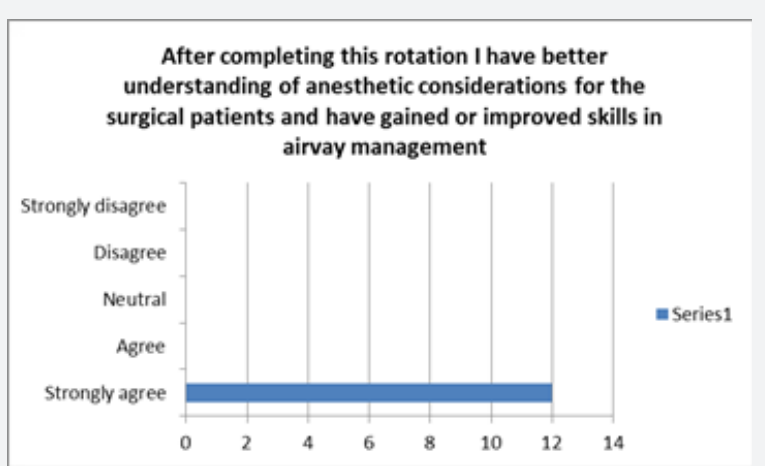

Figure 6: Post-rotation Program evaluation by participants (examples of responses).

The $360^{\circ}$ Program and Curriculum evaluation demonstrated a great degree of enthusiasm from both sides - preceptors and participants. Both teams were viewing CDT as an important practice-based team building exercise, a valuable learning tool and a great teaching opportunity (Table 1).

\section{Discussion}

A high level of practitioner's technical skills is not enough for the contemporary operating room to function effectively. Complexity of the tasks, lack of time, low tolerance for mistakes and corresponding high level of stress make it impossible for even a highly skilled physician to perform safely at his/her full capacity. All the above makes teambuilding a task of utmost importance for any operating suite. Currently there are multiple activities available to build functional teams. They can be divided into two main categories:

Table 1: Evaluation of teaching residents.

\begin{tabular}{|c|c|c|c|c|}
\hline Strongly Disagree & Disagree & Agree & Strongly Agree & \\
\hline I was shown respect as a person by the teaching resident & & & & 15 \\
\hline The teaching resident invited others' thoughts in patient care discussion & & & & 15 \\
\hline The teaching resident admitted when he/she did not know something & & & 2 & 13 \\
\hline The teaching resident appeared to enjoy teaching & & & & 15 \\
\hline The teaching resident was available to me as needed & & & 1 & 14 \\
\hline During my experience, the resident teacher invited questions and discussion & & & 1 & 14 \\
\hline The teaching resident asked questions in a nonthreatening manner & & & & 15 \\
\hline The teaching resident asked questions that stimulate problem-solving & & & 3 & 12 \\
\hline The teaching resident supported statements with evidence & & & 3 & 12 \\
\hline The teaching resident provided guidance to appropriate reading materials & & & 5 & 10 \\
\hline The teaching resident was enthusiastic about anesthesiology & & & & 15 \\
\hline The teaching resident helped me to improve my airway assessment skills & & & 1 & 14 \\
\hline The teaching resident provided opportunities to practice technical skills & & & 1 & 14 \\
\hline The teaching resident gave feedback on good work & & & 1 & 14 \\
\hline The teaching resident provided constructive feedback on areas needing improvement & & & 1 & 14 \\
\hline The teaching resident helped me to identify and resolve learning issues related to patient care & & & 1 & 14 \\
\hline
\end{tabular}




\begin{tabular}{|c|c|c|}
\hline The teaching resident explained concepts in a clear and concise manner & 1 & 14 \\
\hline The teaching resident made an effort to make me feel like part of the team & & 15 \\
\hline $\begin{array}{l}\text { Being paired with a teaching resident was a valuable addiction to my experience on the } \\
\text { rotation }\end{array}$ & & 15 \\
\hline I would recommend using the teaching resident approach in future anesthesiology rotations & & 15 \\
\hline
\end{tabular}

a) Simulation- based (Moca, Helps)

b) Non-simulation based (Teamstepps, Healthcare Adventures® (Hca)

Despite the fact that all of these activities were proven to be highly effective, none is utilizing a mechanism specifically designed to improve relationships between the anesthesiology and surgical staff and facilitate interpersonal communication and professional interaction among different disciplines during the early stages of subspecialty training. In order to establish an effective line of communication team members must to learn and understand each other's professional language. However, current medical training is focusing primarily on acquiring a specialtyrelated knowledge and practical skills which makes it very difficult for the specialists to cross subspecialty barriers in case of emergencies.

\section{Conclusion}

Cross-departmental educational approach teaches residents the basics of cross-specialty skills at the beginning of a professional training. Acquiring cross-specialty skills and knowledge helps residents to improve interpersonal communication, professional behavior and confidence. CDT helps to restore the sense of partnership in perioperative patients' care, which eventually may improve quality of care and the clinical outcome.

This work is licensed under Creative Commons Attribution 4.0 License DOI: 10.19080/JAICM.2019.08.555737

\section{Acknowledgments}

\section{Mikhail Chernov}

Role: This author helped design the study, conduct the study, analyze the data, and write the manuscript

\section{Angela Vick}

Role: This author helped conduct the study and write the manuscript

\section{Sujatha Ramachandran}

Role: This author helped analyze the data

\section{Ellise Delphin}

Role: This author helped analyze the data and write the manuscript.

\section{References}

1. Allison L, Grady (2010) Virtual Mentor 12(1): 24-26.

2. Makary MA, Sexton JB, Freischlag JA, Holzmueller CG, Millman EA, et al. (2006) Operating room teamwork among physicians and nurses: teamwork in the eye of the beholder. J Am Col Surg 202(5): 746-752.

3. Vincent J Kopp, Audrey Shafer (2000) Anesthesiologists and Perioperative communication. Anesthesiology 93(2): 548-555.

4. Halverson AL, Walsh DS, Rikkers L (2012) Leadership skills in the OR, Part 1: Communication helps surgeons avoid pitfalls. The Bulletin of the Americal Collage of Surgeons 97(5): 8-14.

\section{Your next submission with Juniper Publishers will reach you the below assets}

- Quality Editorial service

- Swift Peer Review

- Reprints availability

- E-prints Service

- Manuscript Podcast for convenient understanding

- Global attainment for your research

- Manuscript accessibility in different formats

( Pdf, E-pub, Full Text, Audio)

- Unceasing customer service

\section{Track the below URL for one-step submission}

https://juniperpublishers.com/online-submission.php 